\title{
Effects of Mecamylamine on the Golgi Recurrent Collateral-Renshaw-Cell Synapse in the Spinal Cord
}

\author{
S. Ueki, K. Koketsu, and E. F. Domino ${ }^{1}$ \\ Department of Pharmacology, University of Michigan, Ann Arbor, Michigan, and \\ Department of Psychiatry, University of Illinois, Chicago, Illinois \\ Received August 19, 1960
}

The fact that mecamylamine is a secondary amine with "nicotinic" blocking properties suggested it would act at the Golgi recurrent collateral-Renshaw-cell synapse in the spinal cord. Glass micropipettes were used to obtain extracellular Renshaw-cell discharges due to antidromic ventral root stimulation in cats anesthetized with pentobarbital. The effects of mecamylamine, hexamethonium, physostigmine, and nicotine given intravenously were determined in this preparation. It was found that mecamylamine reduced the terminal portions of the repetitive discharge of Renshaw cells to antidromic stimulation. The stimulant effect of physostigmine and nicotine on Renshaw cells was blocked by mecamylamine. Hexamethonium in similarly effective ganglionic blocking doses had no effect.

\section{Introduction}

Mecamylamine is unique among ganglionic blocking agents in that it is a secondary amine $(8,9,10)$. On the basis of its side effects, which include central nervous system symptoms, it appears to penetrate the blood-brain barrier more easily than ganglionic blocking agents like hexamethonium, which contain quaternary nitrogen atoms. Mecamylamine is a more effective antagonist of nicotine than hexamethonium (10).

Eccles and his associates have shown that the Golgi recurrent collateral on the Renshaw inhibitory neuron in the spinal cord behaves pharmacologically like a "nicotinic"-type cholinergic synapse $(1,2,3,4,5)$. The

1 Supported in part by a grant from the Tobacco Industry Research Committee and grant B-1650, USPHS. An abstract for this paper was presented before the American Society for Pharmacology and Experimental Therapeutics meeting in Miami, Florida, August 1959 (11). Dr. Ueki is located in the Department of Pharmacology, School of Medicine, University of Kyushu, Fukuoka, Japan; Dr. Koketsu, in the Department of Psychiatry, University of Illinois, Chicago 12 , Illinois. 
fact that mecamylamine is a secondary amine with nicotinic blocking properties suggested that it would easily penetrate the blood-brain barrier and exert an action at this synapse. This hypothesis was confirmed experimentally. The results obtained constitute the basis of this report.

\section{Methods}

Twenty-one adult cats of both sexes were used. They were anesthetized with pentobarbital given intraperitoneally in a dose of $25 \mathrm{mg} / \mathrm{kg}$. Additional doses of $10 \mathrm{mg} / \mathrm{kg}$ were given periodically to maintain light general anesthesia. After rigid fixation of the cat in an appropriate supporting frame, the spinal cord was exposed surgically from L4 to L7. The dorsal roots were sectioned usually at the level of L6 to L7. The ventral roots of these segments were cut distally. The proximal stumps were prepared for electrical stimulation. The spinal cord was transected at T10 in order to eliminate the influences of higher centers and to prevent spontaneous movements of the lower half of the body. A glass micropipette of approximately $5 \mu$ at its tip filled with $3 M \mathrm{KCl}$ was passed from the dorsolateral to ventromedial portion of the spinal cord into the Renshaw-cell interneuron pool. After patient searching, extracellular potentials were obtained following antidromic stimulation of the ventral root. The parameters of electrical stimulation were square-wave pulses of $0.1-\mathrm{msec}$ duration, of 1 to 10 volts, repeated every $5 \mathrm{sec}$. The electrical activity of the Renshaw cells was recorded with an appropriate cathode follower connected to an amplifier. The signals were displayed on a dual-beam cathode-ray oscilloscope and recorded photographically by means of a camera. All drugs were administered intravenously. The dosage was calculated on the basis of the salt.

\section{Results}

Following antidromic stimulation of the ventral roots, Renshaw-cell discharges were recorded extracellularly for variable periods of time. With excellent preparations it was possible to record from an individual Renshaw cell for periods longer than 45 min. Usually after 30 min Renshawcell activity seemed to deteriorate. Minimal to no spontaneous activity was observed. The principal effect of mecamylamine was to decrease the terminal discharges of the Renshaw cell to antidromic stimulation. In Fig. 1, panel A, is illustrated a representative record of the normal Renshaw-cell activity to antidromic stimulation of the ventral root. As has been described previously by many others, the Renshaw cell shows initial fast-frequency discharges which gradually diminish with time. In ap- 
proximately $5 \mathrm{~min}$ after the intravenous administration of .mecamylamine in a dose of $0.5 \mathrm{mg} / \mathrm{kg}$, the frequency of the terminal Renshaw-cell activity was reduced (Fig. 1, panel B). Increasing doses of mecamylamine progressively decreased the terminal phases of the repetitive firing of the Renshaw cell. As can be seen in panel $\mathrm{C}$, an additional $1.0 \mathrm{mg} / \mathrm{kg}$ of mecamylamine given intravenously reduced further the terminal activity.
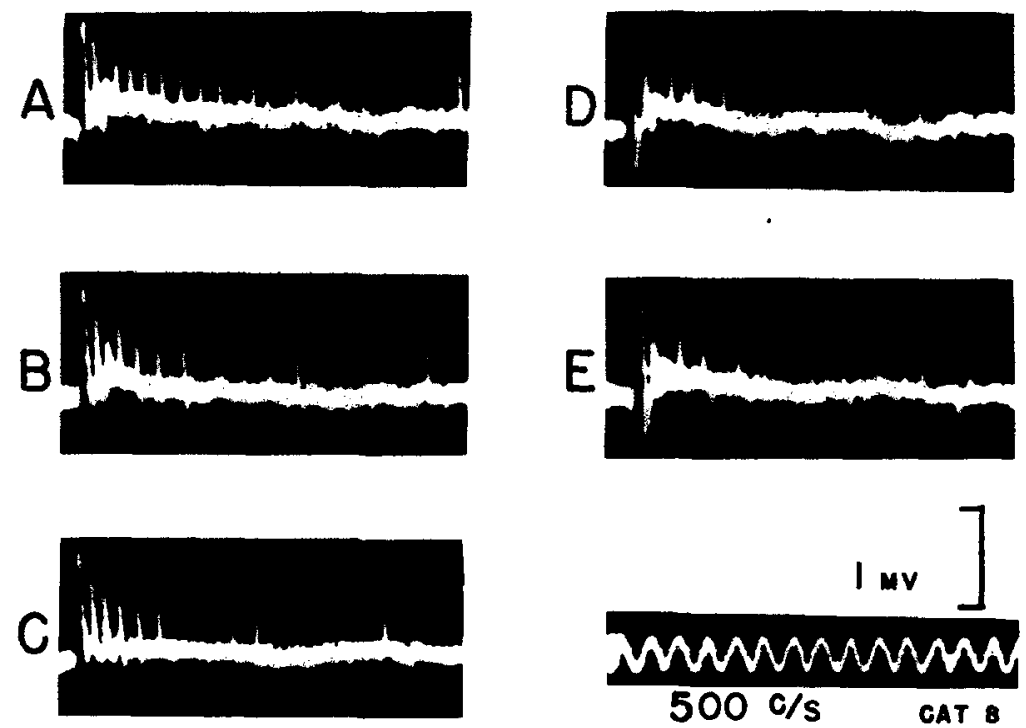

Fig. 1. Effect of mecamylamine on Renshaw-cell activity. A, control activity elicited by antidromic stimulation of ventral roots $\mathrm{L} 6$ and L7. Parameters of stimulation were square wave pulses of $0.1 \mathrm{msec}$ duration, 3 volts, every $5 \mathrm{sec}$. B, $6 \mathrm{~min}$ after mecamylamine $0.5 \mathrm{mg} / \mathrm{kg}$ given intravenously. $\mathrm{C}, 14 \mathrm{~min}$ after an additional $1.0 \mathrm{mg} / \mathrm{kg}$ of mecamylamine given intravenously. $\mathrm{D}, 5 \mathrm{~min}$ after additional 1.0 $\mathrm{mg} / \mathrm{kg}$ of mecamylamine given intravenously. E, $27 \mathrm{~min}$ later. Voltage calibration and time base shown apply for all panels.

This effect was even more enhanced after an additional $1.0 \mathrm{mg} / \mathrm{kg}$ of mecamylamine, as illustrated in panel $\mathrm{D}$. In panel $\mathrm{E}$, is illustrated the Renshaw-cell activity approximately $30 \mathrm{~min}$ after the administration of mecamylamine in an accumulative dose of $2.5 \mathrm{mg} / \mathrm{kg}$. Similar effects were observed in ten different animals. Recovery from mecamylamine was not obtained in view of the fact that Renshaw-cell activity seldom could be recorded for periods beyond 45 min to 1 hour.

An elaborate statistical analysis of the effects of mecamylamine were 
not undertaken. However, in the interest of quantification of the results the pooled number of Renshaw-cell discharges per five photographic frames following antidromic stimulation of the ventral roots of four cats were counted before and 10 to $15 \mathrm{~min}$ after mecamylamine given in a dose of $1.0 \mathrm{mg} / \mathrm{kg}$. The duration of the oscilloscope sweep was approximately $50 \mathrm{msec}$. During this time interval before mecamylamine the mean \pm S.E. of the number of Renshaw-cell discharges was $14.9 \pm 0.82$. After mecamy-
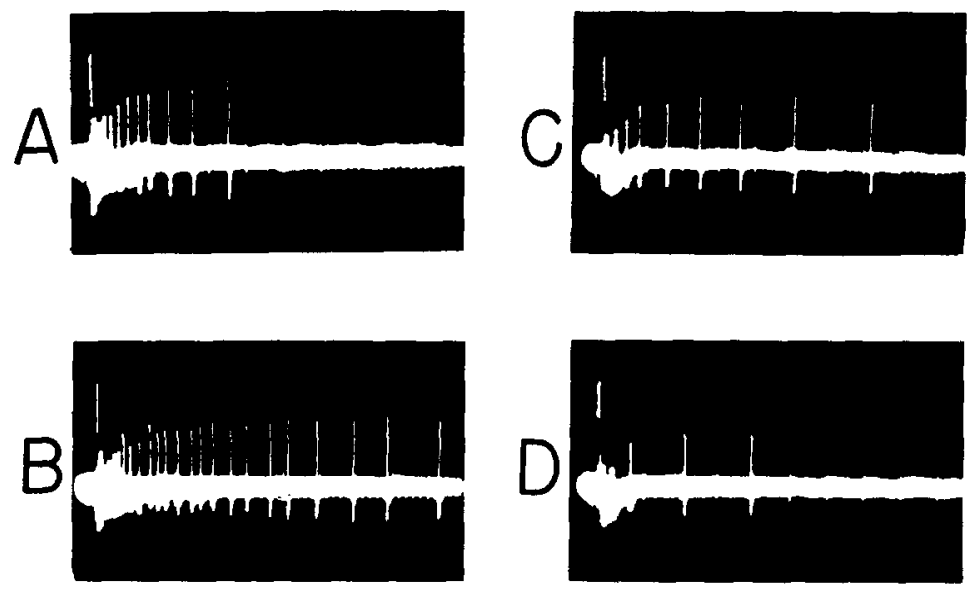

CAT II

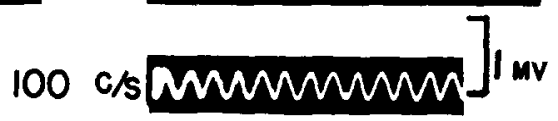

Fic. 2. Fffects of physostigmine and mecamylamine on Renshaw-cell activity. A, control activity following antidromic stimulation. Same parameters of stimulation as in the previous figure except the voltage for antidromic stimulation was 5 volts. B, $3 \mathrm{~min}$ after $300 \mu \mathrm{g} / \mathrm{kg}$ of physostigmine given intravenously. $\mathrm{C}, 10 \mathrm{~min}$ after $0.5 \mathrm{mg} / \mathrm{kg}$ of mecamylamine given intravenously. $\mathrm{D}, 8 \mathrm{~min}$ after a second dose of $1.0 \mathrm{mg} / \mathrm{kg}$ of mecamylamine given intravenously.

lamine it was $8.9 \pm 0.42$. This reduction was statistically significant with a $P$ value of $<0.001$, as determined by the paired comparison student " $t$ " test. It is to be noted that mecamylamine only reduced the mean number of discharges and did not completely block them.

Not only could mecamylamine alone reduce the activity of Renshaw cells that were fired antidromically, but it could also block the action of physostigmine. In panel A of Fig. 2, is shown the control Renshaw-cell activity from antidromic stimulation of a ventral root. Three minutes after the administration of physostigmine, in a dose of $300 \mu \mathrm{g} / \mathrm{kg}$ given 
intravenously, Renshaw-cell activity was markedly prolonged, as illustrated in panel B, Fig. 2. After the administration of $0.5 \mathrm{mg} / \mathrm{kg}$ of mecamylamine, this enhanced activity was reduced toward control levels (panel $\mathrm{C}$, Fig. 2). The addition of another $1.0 \mathrm{mg} / \mathrm{kg}$ of mecamylamine even further reduced this activity. After an additional dose of $1.0 \mathrm{mg} / \mathrm{kg}$ the activity of the Renshaw cells was decreased over control levels in a manner similar to those preparations that had no physostigmine. Similar effects could be observed in six animals.
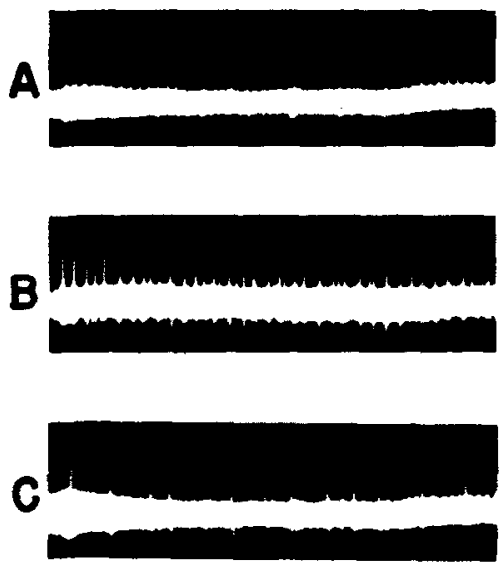
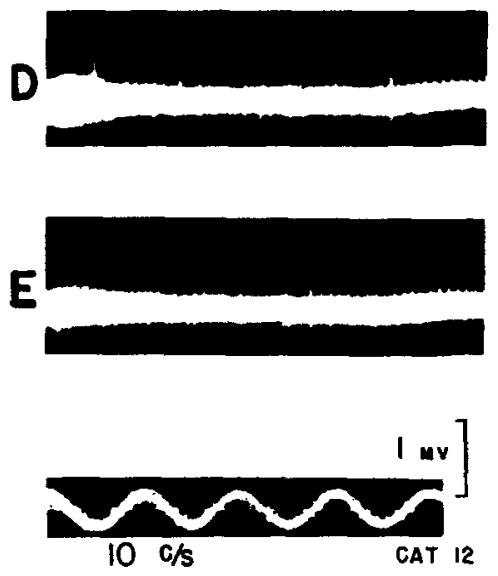

Fic. 3. Effects of nicotine and mecamylamine on spontaneous Renshaw-cell activity. A, no spontaneous discharges were observed during the control period shown. B, $2 \mathrm{~min}$ after $20 \mu \mathrm{g} / \mathrm{kg}$ of nicotine given intravenously. C, $15 \mathrm{sec}$ after $1.0 \mathrm{mg} / \mathrm{kg}$ of mecamylamine given intravenously. D, $30 \mathrm{sec}$ later. E, $1 \mathrm{~min}$ after the intravenous administration of mecamylamine. Note the rapid onset of mecamylamine against the discharges elicited by nicotine as compared to its slower onset of action on antidromically evoked Renshaw-cell activity.

As described previously in pentobarbital-anesthetized animals, normally minimal to no spontaneous Renshaw-cell discharges were observed. After the administration either of physostigmine, and especially of nicotine, spontaneous cell discharge was clearly increased. Nicotine in doses of $20 \mu \mathrm{g} / \mathrm{kg}$ given intravenously was extremely effective in increasing the spontaneous discharge. As can be seen in Fig. 3, panel A, no spontaneous discharges were seen in this particular portion of the record. Within 2 min after the administration of nicotine marked spontaneous Renshaw-cell activity was observed (Fig. 3, panel B) even though there was no antidromic stimulation of the ventral root. Mecamylamine in 
doses of $1 \mathrm{mg} / \mathrm{kg}$ was very effective in reducing this spontaneous discharge, as illustrated in panels $\mathrm{C}, \mathrm{D}$, and $\mathrm{E}$. This effect of mecamylamine occurred within a minute and was therefore much quicker in onset than that ordinarily observed on the effects of antidromic stimulation upon the Renshaw cells.

The effects of hexamethonium in doses of 5 to $10 \mathrm{mg} / \mathrm{kg}$ given intravenously were determined on Renshaw-cell activity elicited by antidromic stimulation of the ventral root. In six animals hexamethonium had no effect on Renshaw-cell activity.

\section{Discussion}

Perhaps the best evidence of neurohumoral transmission in the central nervous system is that involving the Golgi recurrent collaterals of spinal motoneurons synapsing on Renshaw inhibitory interneurons. The investigations of Eccles and his colleagues $(1,2,3,4,5)$ showed that transmission across this synapse is probably mediated by acetylcholine. The intraarterial administration of anticholinesterases, like physostigmine and TEPP, caused a marked prolongation of the firing of Renshaw inhibitory interneurons. On the other hand dihydro- $\beta$-erythroidine depressed transmission across this synapse. Atropine was much less effective in this regard. In general substances with a quaternary nitrogen were relatively ineffective. Thus, transmission was not affected by either $d$-tubocurarine or neostigmine. However, acetylcholine itself, in large doses intraarterially, did stimulate Renshaw cells but there was considerable variability.

Subsequently these investigators $(1,2,3,5)$ showed that the intraarterial administration of nicotine stimulated Renshaw cells more effectively than acetylcholine, whereas acetyl- $\beta$-methylcholine, carbaminocholine, arecoline, and succinylcholine were ineffective. On the basis of the responses to various agents it appears logical to conclude that this is essentially a cholinergic "nicotinic"-type synapse. Studies of this synapse are complicated because of the existence of a blood-brain barrier which decreases the penetrability of compounds with a positive charge. However, the somewhat anomalous effects of drugs on this synapse cannot be wholly explained on the basis of a blood-brain barrier. More recently, Curtis and Eccles $(1,2)$ have offered evidence of another diffusional barrier surrounding the terminals of the motor axon collateral on the Renshaw cell. They called this the synaptic barrier. Evidence for such a barrier was obtained by means of a five-barreled micropipette for the electrophoretic injection of drugs directly in the vicinity of the Renshaw cell. Both 
acetylcholine and nicotine were very effective in stimulating Renshaw cells when applied locally. Acetyl- $\beta$-methylcholine, carbaminocholine, arecoline, and succinylcholine were not very effective when applied electrophoretically. At most a low-frequency discharge of Renshaw cells was produced. Neostigmine and edrophonium locally applied markedly accentuated the action of acetylcholine. When applied locally, $d$-tubocurarine was relatively ineffective in depressing the responses due to electrophoretically injected acetylcholine or that due to antidromic stimulation of the ventral roots. Decamethonium injected locally had little effect on Renshaw activity due to antidromic stimulation of the ventral root, but prolonged slightly the effects of locally applied acetylcholine. Electrophoretic injection of dihydro- $\beta$-erythroidine was effective in reducing the activity of Renshaw cells as it was following intraarterial administration.

Mecamylamine appears to be as effective as dihydro- $\beta$-erythroidine $(4,7)$ in reducing Renshaw-cell discharge. This experimental conclusion would be expected in view of the fact that the Renshaw cell-Golgi recurrent collateral synapse appears to be of the "nicotinic" cholinergic type. This effect of mecamylamine occurs in doses that produce ganglionic blockade. On the other hand, hexamethonium in doses considerably above those producing ganglionic blockade had no effect upon the Renshaw-cell activity. Therefore, the effects of mecamylamine cannot be the result of hypotension. Although in massive doses hexamethonium can penetrate the blood-brain barrier of rats (6), in the doses used in this study in cats it had no action on this inhibitory spinal cord synapse. This could be related either to failure to penetrate or no appreciable pharmacological action at this spinal cord site. It would appear that the failure to penetrate is probably the more important factor.

It is of considerable interest that mecamylamine has central nervous system side effects, such as tremor and mental aberrations including delusions or hallucinations, in addition to those characteristic of peripheral ganglionic blockade. Since central nervous system side effects are much less common, apparently the central actions of this compound are minimal compared to its peripheral effects. Although the present study would tend to suggest that respectable peripheral ganglionic blocking doses have a detectable action on Renshaw-cell terminal discharge, it may very well be that this does not interfere markedly with the normal physiological inhibition of anterior horn cells. Perhaps for this reason no appreciable central manifestations are noted with mecamylamine in therapeutically effective doses in man. 
The effectiveness of mecamylamine to depress the Golgi collateralRenshaw-cell synapse is additional pharmacological evidence that this is a "nicotinic"-type cholinergic synapse in the central nervous system.

\section{References}

1. Curtis, D. R., and R. M. Eccles, The excitation of Renshaw cells by pharmacological agents applied electrophoretically. J. Physiol. London 141: 435-445, 1958.

2. Curtis, D. R., and R. M. Eccles, The effect of diffusional barriers upon the pharmacology of cells within the central nervous system. J. Physiol. London 141: $446-463,1958$.

3. Curtis, D. R., J. C. Eccles, and R. M. Eccles, Pharmacological studies on spinal reflexes. J. Physiol. London 136: 420-434, 1957.

4. Frctes, J. C., P. FatT, and K. Koketsu, Cholinergic and inhibitory synapses in a pathway from motor-axon collaterals to motoneurons. J. Physiol. London 126: 524-562, 1954.

5. ECCles, J. C., R. M. Eccles, and P. FATt, Pharmacological investigations on a central synapse operated by acetylcholine. J. Physiol. London 131: 154-169, 1956.

6. Levine, R. R., Presence of certain onium compounds in brain tissue following intravenous administration to rats. Nature 184: 1412-1414, 1959.

7. Longo, V. G., W. R. Martin, and K. R. UnNa, A pharmacological study of the Renshaw cell. J. Pharmacol. Exptl. Therap. 129: 61-68, 1960.

8. Rowe, G. G., C. A. Castillo, D. H. White, Jr., D. J. Freeman, and G. M. Maxwell, Hemodynamic effects of Mecamylamine. Federation Proc. 17: $407,1958$.

9. Stone, C. A., M. L. Torchlana, A. Navarro, and K. H. Beyer, Ganglionic blocking properties of 3-methylaminoisocamphane hydrochloride (Mecamylamine): A secondary amine. J. Pharmacol. Exptl. Therap. 117: 169-183, 1956.

10. Stone, C. A., K. L. Meckelnburg, and M. L. Torchiana, Antogonism of nicotine-induced convulsions by ganglionic blocking agents, Arch. intern. pharmacodynamie 117: 419-434, 1958.

11. UeKi, S., K. Koketsu, and E. F. Domino, Some actions of mecamylamine and nicotine on the central nervous system. The Pharmacologist 1: 58, 1959. 